\title{
LINHA DE MÓVEIS NÓRDICA ESCANDINAVA: 0 processo projetual de mobiliários
}

\author{
Maria Eduarda Ramos Alves Soares \\ Alessandra Van Der Ley \\ Janaina Freitas Silva de Araúio
}

\begin{abstract}
Resumo: As emoções são influenciadores na capacidade que o ser humano tem em compreender e interagir com tudo a sua volta. Inconscientemente, o homem cria ligações afetivas com os produtos, e esses laços levam os consumidores a comprar algo (mesmo sem precisar). Para que um produto conecte-se ao consumidor, Donald Norman (2004) diz que a estrutura cerebral humana é resultado de três níveis emocionais, portanto, para que os produtos desenvolvidos sejam bem-sucedidos em atender as necessidades do consumidor, precisa alcança-los. Compondo esses níveis estruturais do cérebro, têm-se: o visceral, o comportamental e o reflexivo. Conforme tal perspectiva e diante da proposta da experimentação projetual no âmbito acadêmico para a criação de linha de móveis, desenvolvemos etapas para a realização da atividade. Este artigo propõe-se a apresentar e explanar acerca das etapas realizadas na concepção do projeto para a linha de mobiliário de temática e concepção nórdica escandinava.
\end{abstract}

Palavras-chave: mobiliário, projeto de linha, design emocional.

\section{INTRODUÇ̃̃O: ENTENDIMENTO DA NECESSIDADE E O PÚBLICO-ALVO}

Historicamente, muitos produtos desenvolvidos por artífices eram destinados para nobreza, por demandarem tempo no processo de detalhamento das peças componentes. Porém, a industrialização é introduzida e possibilita grandes produções, mas com qualidade inferior da produção dos artífices.

O público-alvo modista consome tendências, não se preocupando muitas vezes com o preço ou nível técnico (FAGGIANI, 2006). Tendo em vista que esses consumidores têm interesse por design e procuram inovações no mercado, as empresas consolidadas desenvolvem produtos que se tornam objetos de desejos da massa. Entre essas empresas conhecidas, pode-se citar: Tok\&Stok, Florense, Ikea, etc. São empresas com setores exclusivos para criação e design e que apostaram em produção modular ou sob medida de acordo com a necessidade do cliente.

Após analisar as tendências atuais nos sites dessas empresas, incorporamos a dinâmica destas para tentar atingir, além desse público modista, outros públicos e os seus diferentes modos de vida, através do lançamento de linhas que personifiquem os espaços. Também consideramos outros aspectos como a segurança e a funcionalidade dos produtos, não elencando apenas o aspecto estético do que foi pesquisado, compreendo, portanto, o mobiliário como uma obra que cause deleite quando observado, mas que atenda as necessidades ergonômicas e práticas do indivíduo. 
Assim, observou-se a oportunidade de desenvolver uma linha de mobiliários que possibilitem personificar os espaços através de mecanismos que se modifiquem, além de ser funcional e criar relação de proximidade com o público modista através do design emocional.

\section{COMPREENDENDO A RELAÇÃO MOBILIÁRIO X PÚBLICO ALVO}

O objetivo do projeto é desenvolver uma linha com oito mobiliários, cada qual com seus níveis de complexidade. Para tal atividade ser realizada com sucesso e diante das informações obtidas anteriormente, fizemos uso de algumas ferramentas nessa etapa inicial do projeto para compreender melhor a relação entre o público alvo modista e os mobiliários consumidos por eles.

Uma das ferramentas utilizadas para a compreensão da correlação entre usuário e mobiliário foi o brainstorming . Ele é uma técnica utilizada no projeto para explorar ideias acerca da problematização, visando expor pontos de vistas para chegar a denominadores comuns, possibilitando o melhor aproveitamento de diversos pensamentos e experiências para alcance de uma solução final.

Também foi possível desenvolver um mapa mental (BUZAN. 2005) no projeto que serviu como organizador para o excesso de informações oriundas do brainstorm?. Foram priorizados os pensamentos e informações em categorias (estéticas, funcionais, segurança, transporte, etc.) para posteriormente identificar oportunidades e encontrar soluções para os problemas respectivos a cada um destes.

Além dessas técnicas, foi desenvolvido um mapa de interessados e impactos pelo desenvolvimento dos mobiliários (Quadro 01). O processo de identificação de atingidos de forma direta ou indireta pelo projeto possibilita a compreensão das necessidades e dos requisitos para o mesmo, norteando capacidades e restrições.

Quadro 01 - Interessados e impactados. Fonte: Elaborado pelo autor, com base na pesquisa realizada.

\begin{tabular}{|l|l|c|}
\hline \multirow{2}{*}{ CLASSE } & INTERESSADOS E IMPACTADOS & PRIORIDADE \\
\hline \multirow{2}{*}{$\begin{array}{l}\text { Usuários } \\
\text { Finais }\end{array}$} & Transportadoras & 1 \\
\hline \multirow{2}{*}{ Internos } & Fábricas & 2 \\
\cline { 2 - 3 } & Fornecedores & 3 \\
\hline Intermediários & Público-alvo & 3 \\
\cline { 2 - 3 } & Escritório & 2 \\
\hline
\end{tabular}

O emprego destas ferramentas criativas justifica-se pela objetividade do projeto em atender também aos aspectos do conceito que se busca alcançar com os mobiliários: design emocional; funcionalidade; inovação e identidade própria. A proposta para o desenvolvimento do projeto surge da necessidade de uma empresa em entrar no mercado mobiliário e se consolidar com seus produtos, fazendo uso do apelo à emoção do consumidor, como a sua necessidade prática e funcional de um estilo de vida cada vez 
mais conturbado - estilo este que será discutido mais a frente.

\section{METODOLOGIA PROJETUAL APLICADA}

A metodologia aplicada ao projeto é híbrida unindo propostas de Baxter (2000) e Bonsiepe (2012) para desenvolvimento de projeto a fim de aperfeiçoar as análises, direcionando-as à ótica mercadológica. As fases adotadas por essa metodologia estão presentes no Quadro 02.

Para complementar a análise metodológica, foi desenvolvida a Estrutura Analítica (EAP) (ferramenta utiliza por empresas no gerenciamento de projetos) a fim de organizar, através de um organograma, todas as atividades, subatividades, tarefas e subtarefas que serão essenciais para que o projeto seja concluído. Ela também compreende a análise de riscos que objetiva analisar tanto qualitativa quanto quantitativamente os riscos ao qual o projeto pode se submeter, assim identificando, analisando, elaborando e encontrando respostas para controlar os riscos.

A análise qualitativa de risco foi realizada para identificar todos os procedimentos e técnicas que poderiam ser utilizados no desenvolvimento da linha, baseados na metodologia aplicada. A análise quantitativa de riscos foi utilizada para confirmar os riscos priorizados, durante a execução dos procedimentos e técnicas.

Quadro 02 - Fases projetuais para o desenvolvimento dos mobiliários. Fonte: Elaborado pelo autor, com base na pesquisa realizada.

\section{Fases projetuais para o desenvolvimento dos mobiliários}

\begin{tabular}{|c|l|}
\hline $\mathbf{1}$ & $\begin{array}{l}\text { Exploração das primeiras ideias para testes de mercado: consiste na identificação e } \\
\text { elaboração de ideias para o projeto. Etapa em que serăo realizadas pesquisas para } \\
\text { identificar as necessidades existentes do problema explorado; }\end{array}$ \\
\hline $\mathbf{2}$ & $\begin{array}{l}\text { Especificaçōes de oportunidades e especificaçōes de projeto: problemática já definida e } \\
\text { justificada. Serão realizadas análises de mercado, ergonomia, normas e patentes para } \\
\text { posteriormente chegar à etapa do anteprojeto; }\end{array}$ \\
\hline $\mathbf{3}$ & $\begin{array}{l}\text { Projeto conceitual: utilizar dos requisitos e parâmetros como um estudo preliminar para a } \\
\text { sua realização, fazendo uso de métodos criativos para desenvolver alternativas que } \\
\text { explorem o que foi descrito na etapa anterior; }\end{array}$ \\
\hline $\mathbf{4}$ & $\begin{array}{l}\text { Configuração do projeto: conceito escolhido. Serão exploradas todas as formas possíveis } \\
\text { de fabricação, passando por testes para verificação de possiveis falhas e seus efeitos, } \\
\text { terminando na construçăo de mock-up para aprovação ou rejeiçăo do projeto; }\end{array}$ \\
\hline $\mathbf{5}$ & $\begin{array}{l}\text { Projeto para fabricação: detalhamento do projeto será apresentado de acordo com os } \\
\text { resultados obtidos através das configurações, determinando assim, como o produto será } \\
\text { produzido. }\end{array}$ \\
\hline
\end{tabular}

Posteriormente, foi desenvolvido o cronograma do projeto, elaborado a partir da ferramenta de análise PERT (Program Evaluation and Review Technique )/ CPM (Critical Path Method). Essas ferramentas permitiram compreender quais atividades são predecessoras, quais etapas dependem uma da outra, permitiu estabelecer os prazos para a execução das atividades e o tempo total de execução.

\section{APROFUNDANDO A PESQUUISA: ANÁLISES E DIAGNÓSTICOS}


Segundo os dados apresentados anteriormente sobre o perfil do público alvo, foram realizadas análises por meio de questionários e análise de mercado. Destacaram-se algumas características da linha de mobiliários que desejamos alcançar. As características são: linha de mobiliário que promove a durabilidade e benefício em relação à compra condicionada por estética e funcionalidade exclusiva ao cliente - trabalhando nichos de mercado; atrair o consumidor pela possibilidade de uma combinação entre as peças que possam ser comercializadas por meio de um sistema de fidelidade; explorar o conceito de mobiliário transportável que possa ser transportado com a mudança de uma residência a outra; criar peças de mobiliário que possam ser ambientadas na cozinha e na sala de estar ou no escritório - multifuncionais.

A análise FOFA (Forças, Oportunidades, Fraquezas e Ameaças) (criada por Humphrey entre as décadas de 60 e 70 para a Universidade de Stanford, é uma ferramenta para análise de cenário) também foi realizada visando à prospecção de mercado, a fim de confirmar a oportunidade de uma nova linha conceitual que atendesse ao público alvo modista. Na etapa do projeto conceitual, portanto, tratamos da mensagem a qual a linha passará para o usuário. Foram selecionadas três ideias principais para elaboração do conceito com potencial para serem exploradas e trabalhadas de acordo com os dados obtidos inicialmente e com o briefing².

O conceito nórdico escandinavo foi selecionado de acordo com o levantamento e criação de painéis para estudo do estilo de vida do usuário, expressão do produto e tema visual. Essas informações foram cruzadas com os dados oriundos da aplicação dos questionários com um grupo de 20 indivíduos distintos. Observamos que os usuários possuem como hábito diário a leitura, gostam de produtos funcionais e práticos, mas duráveis, descreveram problemas com as compras apenas durante a etapa de instalação dos móveis nas residências, e não se incomodam em realizar compras em lojas online.

Amplamente difundido nas últimas décadas por meio das mídias sociais (séries, filmes, cultura pop de modo geral), o estilo nórdico ou escandinavo conquistou várias pessoas dos mais diferentes lugares do mundo. Sob a ótica do desenvolvimento mobiliário, a Europa investiu na proposta de decoração e desenho de mobiliário com espaços mais simples, "limpos", neutros e com aspecto atemporal. Esse estilo se tornou desejado por muitas pessoas, agradando e servindo como inspiração para diversas faixas etárias. Mesmo em uma sociedade de consumo tão forte, a busca por um estilo de vida mais minimalista - seja por sensibilização a onda verde ou por tendências.

Caracterizados pela sofisticação e funcionalidade, o estilo nórdico escandinavo é denominado segundo sua influência geográfica e climática. Tais aspectos também estão presentes em seu design, que é pensado para levar mais claridade e luminosidade para os ambientes, uma vez que as regiões nórdicas passam por períodos bem frios e de escuridão no inverno. Mesmo com seu surgimento no século XIX, o reconhecimento do estilo escandinavo só chegou a seu auge no ano de 1950, pois durante o pós II Segunda Guerra Mundial a funcionalidade, simplicidade, minimalismo e os preços acessíveis da produção em larga escala eram a opção mais viável, em decorrência do seu contexto econômico e político da época, além de ser um modo de assumir valores como a neutralidade e a austeridade (CARDOSO, 2008).

Esse modelo de design trouxe a simplificação das formas, eliminando os elementos vernaculares, sendo associada ao Funcionalismo e ao Estilo Internacional (GLACEY, 2001). A primeira vertente, o Funcionalismo, prezava a função como característica determinante do objeto. A partir desse pensamento, originou-se o Estilo Internacional, que foi associado

2 Briefing - é um conjunto de informações ou uma coleta de dados passados em uma reunião para o desenvolvimento de um trabalho ou documento. O briefing deve produzir um roteiro de ação para criar a solução que o cliente procura, ou seja, é como mapear o problema e, com as pistas identificadas, ter ideias para criar soluções 
à Bauhaus (CARDOSO, 2008). Esses novos modelos de design foram então adotados e reafirmados por diversas empresas, em decorrência da expansão das multinacionais europeias, criando diversas outras vertentes, a exemplo do design escandinavo moderno (SCHNEIDER, 2010).

As necessidades encontradas através do diagnóstico acerca do tipo de mobiliário consumido pelos entrevistados pelo questionário possibilitou determinar as características de formas e funções dos produtos. Desse modo, foram pontuados aspectos considerados importantes para cada mobiliário da linha de 8 unidades e, em seguida, utilizamos o Diagrama de Mudge e o QFD (AMARAL, 2006) para atribuir valores ao nível de importância quais desses aspectos.

\section{DESDOBRAMENTO DA FUNCAO DE QUUALIDADE}

A etapa do Desdobramento da Função de Qualidade (QFD) é um método de apoio para o desenvolvimento do produto que tem por objetivo elencar as melhores qualidades que o mesmo deve alcançar de acordo com as expectativas dos consumidores. Para tal, os 8 mobiliários foram divididos de acordo com sua respectiva função principal. Similares de apoiar: compreender o rack, a mesa de centro e a mesa de jantar; Similares de sentar: a cadeira da mesa de jantar, o sofá e a poltrona; e Similares de guardar: a estante e o buffet.

\subsection{QFD DOS SIMILARES DE APOIAR}

Foram consideradas como necessidades do mobiliário: a fácil mobilidade; o conforto; encaixes; resistência; funcionalidade; segurança; preservação dos aspectos ergonômicos; e a expressão do produto. Para isso, os requisitos colocados foram: a largura; altura; montagem e desmontagem; a densidade; comprimento; e a durabilidade. Como aspectos mais importantes elencados pela análise, observamos que a altura, comprimento e a largura são os mais pontuados, e por isso mais importante na etapa de desenvolvimento. Porém, outros requisitos como a densidade e a durabilidade receberam um ótimo peso de avaliação, portanto foram considerados igualmente importantes.

\subsection{OFD DOS SIMILARES DE SENTAR}

Foram consideradas como necessidades do mobiliário: fácil mobilidade; conforto; encaixes; resistência; funcionalidade; segurança; ergonomia; e expressão do produto. E como requisitos: a largura total; largura do assento e do encosto; altura total; altura do assento e do encosto; montar e desmontar; densidade; profundidade; descanso de braços; e resistência a impactos. Após a análise, o requisito com maior porcentagem para esse grupo de mobiliários foi o descanso para os braços, ou seja, essa característica precisa ser desenvolvida de forma que o usuário não sinta fadiga. Porém, requisitos como a largura, altura e profundidade também apresentaram valores elevados, e, portanto, também demandam atenção.

\subsection{OFD DOS SIMILARES DE GUARDAR}

Nesse grupo, as necessidades foram semelhantes ao grupo anterior, sofrendo alteração nos requisitos com a troca do comprimento pela profundidade. Após essa análise dos requisitos prioritários no desenvolvimento do mobiliário, foi visto que a altura, profundidade e a largura são consideradas aspectos com maior peso absoluto.

\section{MÉTODO 635 DOS MOBILIÁRIOS}


Para a elaboração dos esboços e a geração de alternativas após determinas os requisitos nas etapas anteriores, foi utilizado o método 635, gerando diversos desenhos de possíveis soluções por meio da representação gráfica para os mobiliários que procurávamos projetar (Figura 01).

Figura 01 - Alternativas dos similares de apoiar. Fonte: Elaborado pelo autor, com base na pesquisa realizada.

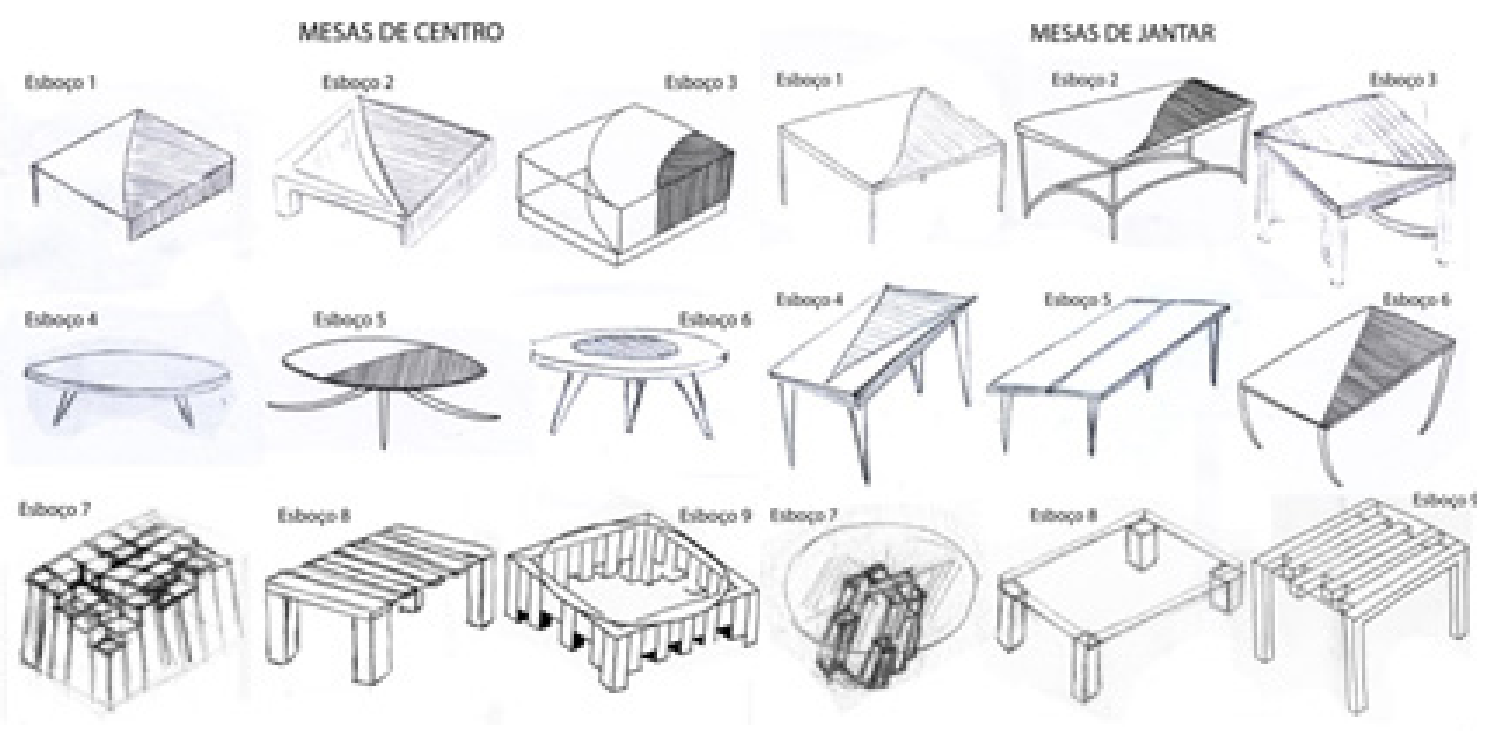

Todas as alternativas são baseadas no conceito do projeto, buscando o equilíbrio entre a função e o design. Assim, foram explorados aspectos com um diferencial - através da união de materiais e formas que, mesmo simples possibilitassem inovação ao móvel. Assim como é possível observar as opções criadas para os similares de apoiar, foram desenvolvidos outros para os similares de sentar (Figura 02).

Figura 02 - Alternativas dos similares de sentar. Fonte: Elaborado pelo autor, com base na pesquisa realizada.

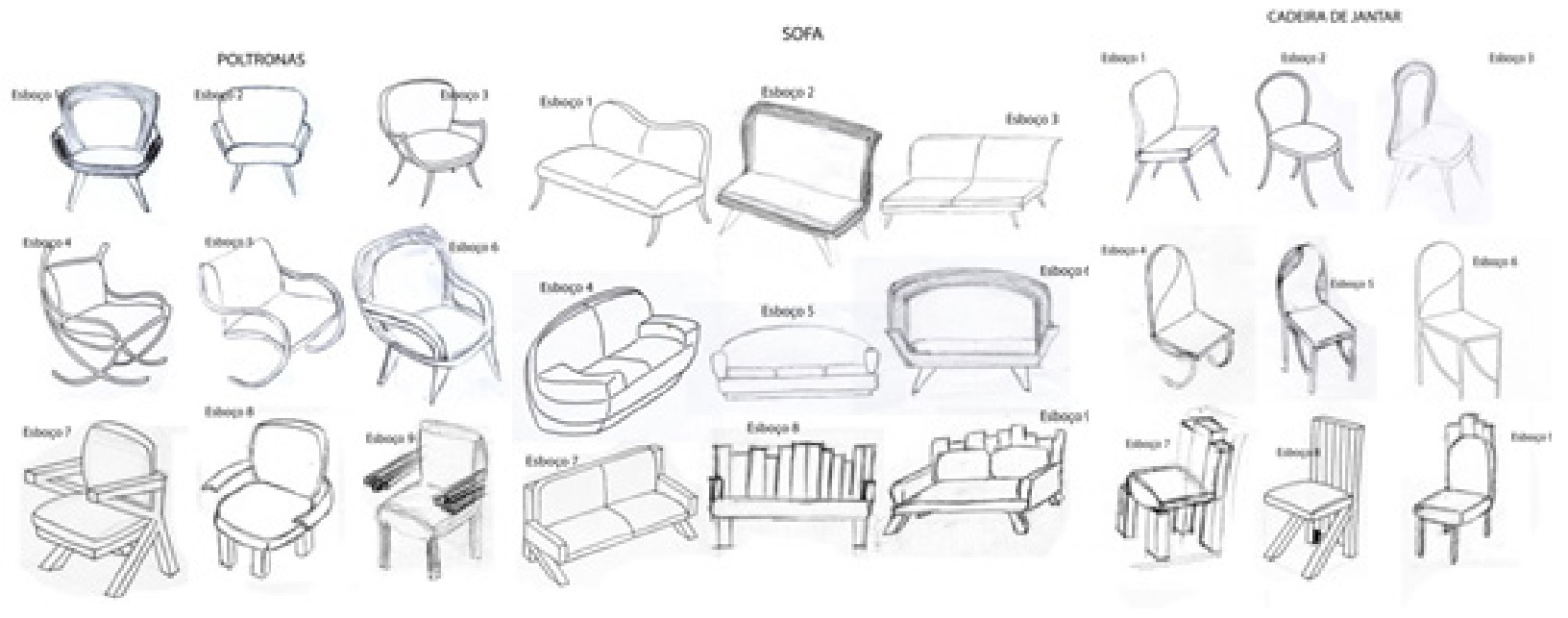

Nos desenhos foram empregados dois aspectos: aplicação de espessuras mais finas, abauladas, misturando materiais naturais como madeira e vidro; e aplicação de volumetria mais robusta, com estrutura mais rígida e espessura mais grossa. A seguir podemos observar as alternativas para os similares de sentar (Figura 03). 
Figura 03 - Alternativas dos similares de guardar. Fonte: Elaborado pelo autor, com base na pesquisa realizada

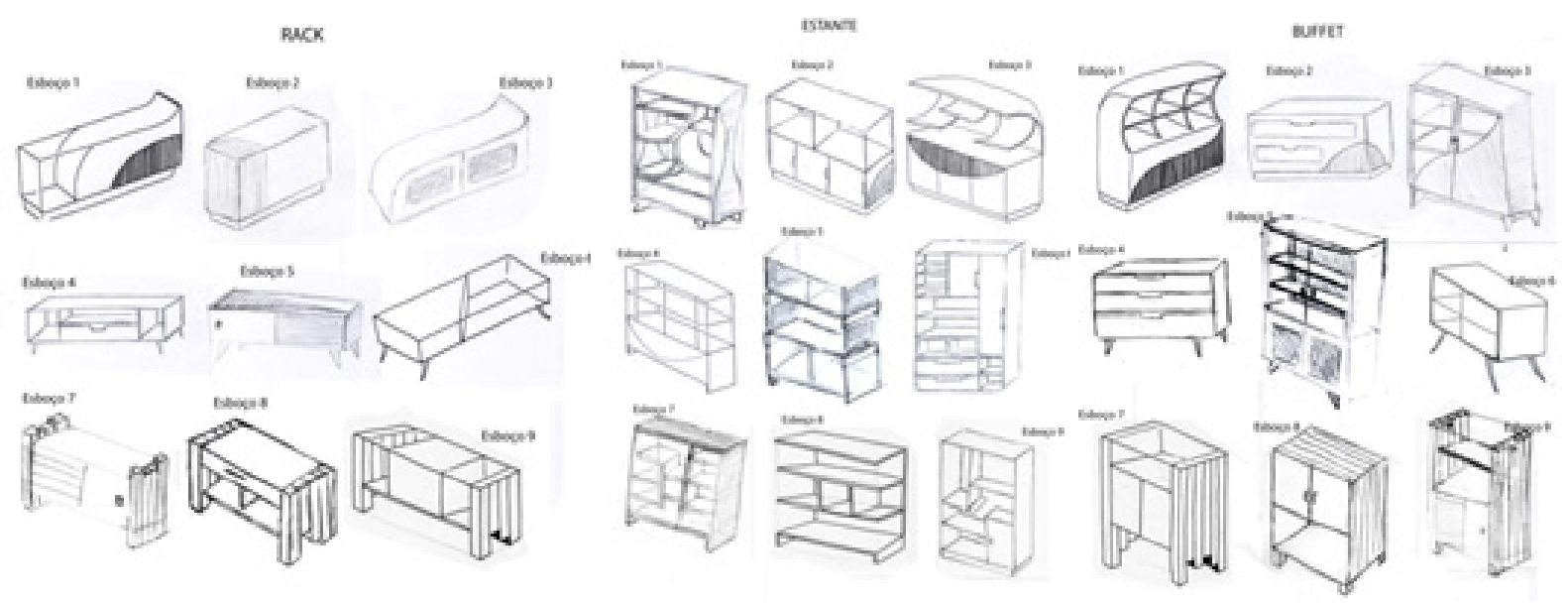

As características de funcionalidade e a expressão do produto mantiveram-se em torno de uma aparência minimalista por meio de superfícies com o material natural e foco no acabamento mais complexo. Buscou-se integrar as opções de 8 mobiliários distintos em funções para uma área comumente integrada em residências: a sala de estar e a sala de jantar. Após o desenvolvimento de todos os esboços, eles foram analisados e pontuados de acordo com os requisitos das etapas anteriores e das informações acerca das necessidades do público alvo modista.

\section{DETALHAMENTO DA ALTERNATIVA}

Assim que usamos a matriz de posicionamento e selecionamos as opções de mobiliários que serviriam de base para o desenvolvimento dos mobiliários, seguimos para a próxima etapa: o detalhamento da alternativa. As alternativas foram detalhadas através de representações realizadas manualmente em escala sem o uso de instrumentos, fornecendo informações do pré-dimensionamento, materiais, processo de fabricação, subsistemas, componentes e padrão cromático (Figura 04). 
Figura 04 - Pré-dimensionamento de algumas das alternativas: mesa de jantar, sofá e estante. Fonte: Elaborado pelo autor, com base na pesquisa realizada.
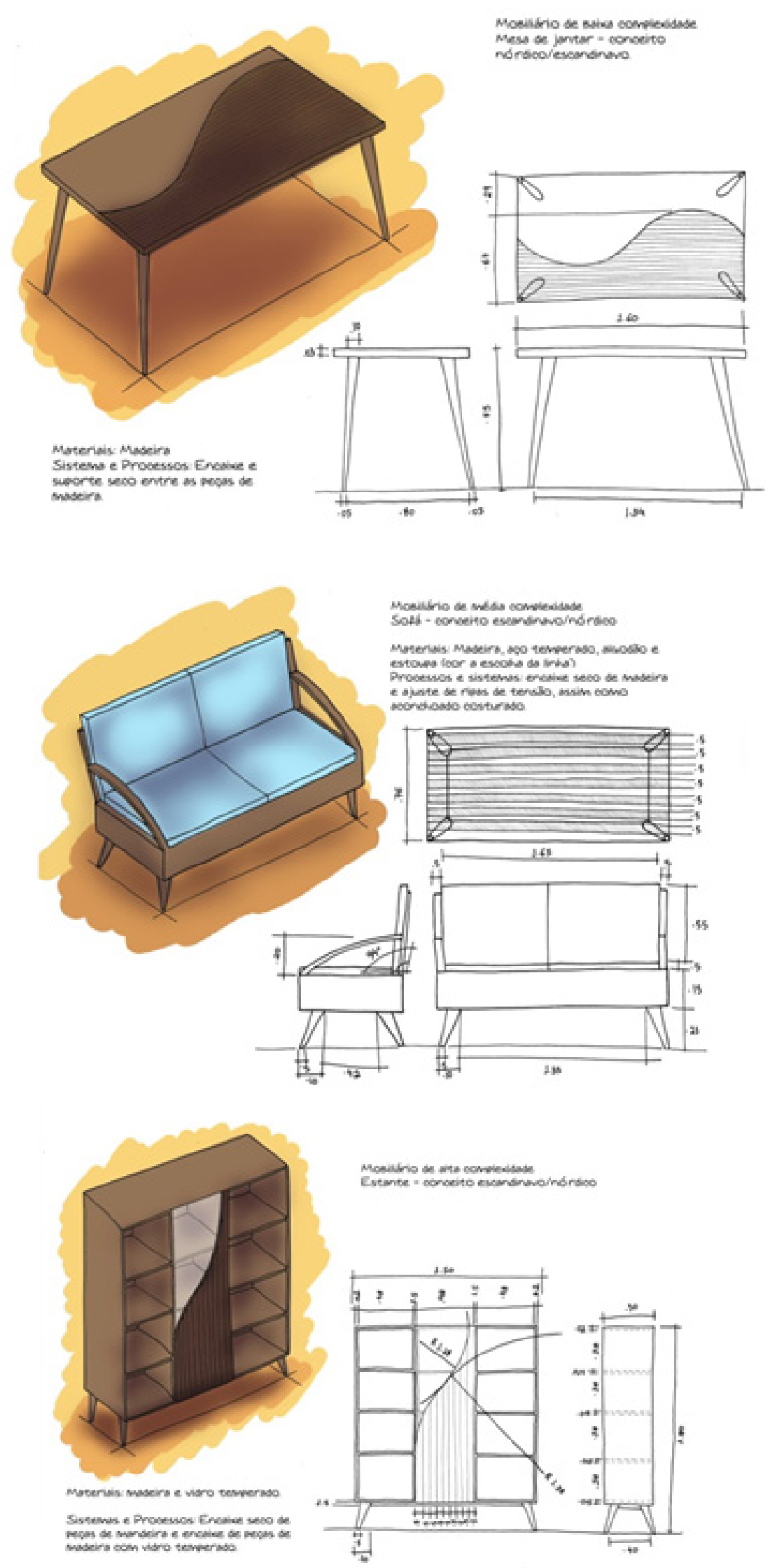

\section{MÉTODO DE TESTES DE USABILIDADE}

Nesta etapa foi realizado o desenvolvimento de mock ups dos mobiliários na escala 
de 1/10 para observação das proporções dos mesmos. Desse modo, podem ser vistos a seguir os modelos (Figura 05).

Figura 05 - Teste de usabilidade dos mobiliários projetados. Fonte: Elaborado pelo autor, com base na pesquisa realizada.

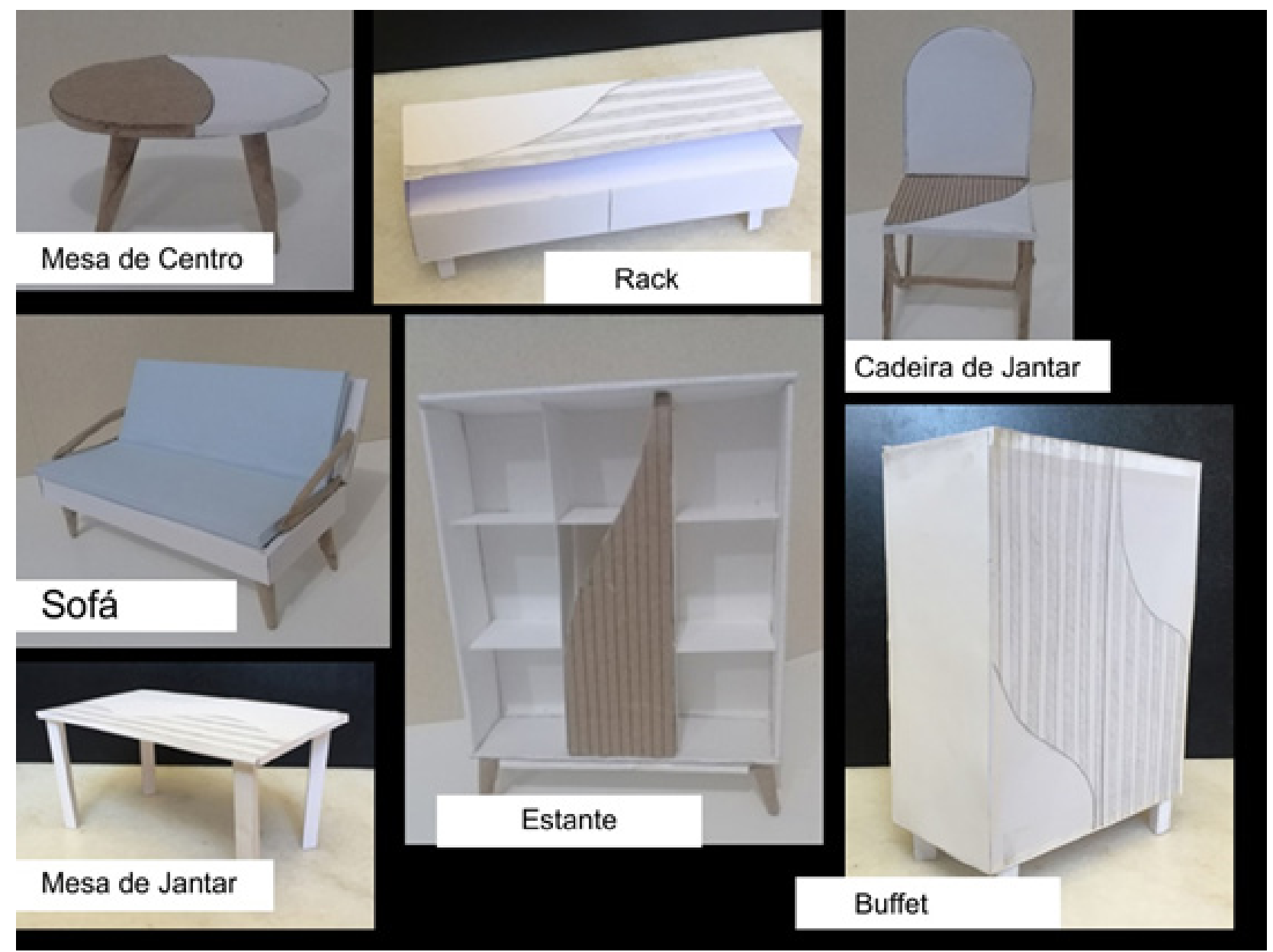

\section{CONSIDERACÕES FINAIS}

Após todas as fases projetivas, encerramos o projeto com o fechamento técnico. Com a pesquisa acerca das empresas já estabelecidas no mercado nacional e o seu método de comércio, conseguimos criar a proposta para a linha de 8 mobiliários para área integrada de sala de estar e jantar com o conceito nórdico escandinavo. É importante destacar, todavia, que os materiais considerados para a execução dos móveis em tamanho real foram elencados de acordo com a disponibilidade nacional. Foram elencados: a madeira pino, o aço inoxidável e o vidro temperado, além do estofado tipo suede.

Os resultados obtidos com o uso das ferramentas projetuais serviram como guias para os primeiros esboços realizados, e aqueles que foram selecionados sofreram as alterações necessárias para atenderem aos objetivos do projeto, de forma a atingir o resultado esperado e identificado nas etapas anteriores.

É importante destacar que essa metodologia é uma abordagem híbrida que, apesar de ser rica em ferramentas projetuais, partiu do conhecimento prático no desenvolvimento de projetos para que as etapas fossem organizadas de maneira mais orgânica, com aspectos de feedback e intercaladas para que cada etapa pudesse desencadear resultados utilizados na próxima etapa.

O projeto da linha de 8 mobiliários destaca-se devido à síntese entre o conceito nórdico escandinavo redesenhado para a modernidade, com ajustes segundo a funcionalidade 
buscada pelo público-alvo e o emprego de materiais acessíveis nacionais. Essa última parte consistiu na escolha de similares aos materiais europeus, pois, apesar de serem semelhantes, não possuem as mesmas propriedades. Tal processo de adaptação, assim como a escolha dos sistemas para funcionamento dos mobiliários segundo sua respectiva função, foi o principal resultado de todo esse processo projetual de mobiliário.

\section{REFERÊNCIAS}

AMARAL et al. Gestão de desenvolvimento de produtos. São Paulo: Saraiva, 2006.

BAXTER, M. Projeto de Produto: guia prático para o design de novos produtos. 2ed. São Paulo: Edgard Blucher, 2000.

BONSIEPE, G. Design como prática de projeto. São Paulo: Blucher, 2012.

BUZAN, T. Mapas mentais e sua elaboração: um sistema definitivo de pensamento que transformará a sua vida. Tradução Euclides Luiz Calloni, Celusa Margô Wosgrau, São Paulo, Cultrix, 2005.

CARDOSO, R. (org.). O design brasileiro antes do design. São Paulo: Cosac Naify, 2005.

CARDOSO, R. Uma introdução à história do design. São Paulo: Blucher, 2008.

FAGGIANI, K. O poder do design: da ostentação à emoção. Brasília, Thesaurus. 2006.

FALLAN, K. Scandinavian Design: alternative histories. New York: Berg, 2012.

GLACEY, J. A história da arquitetura. Tradução: Borges, Luís Carlos; Marcionilo, Marcos. São Paulo: Edições Loyola, 2001.

HUON, M. História ilustrada das antiguidades. São Paulo: Nobel, 1999.

LIMA, H. G. F. Brainstorming. Disponível em: <http://heuberlima.files.wordpress. com/2011/08/senai-requisitos-aula3-brainstorming.pdf>.

PANERO, J. Dimensionamento humano para espaços interiores. 1ạ edição. Editorial Gustavo Gili. Barcelona, Espanha. 2011.

SCHNEIDER, B. Design - uma introdução: o design no contexto social, cultural e econômico. São Paulo: Editora Blücher, 2010.

Sobre as autoras:

Maria Eduarda Ramos Alves Soares (graduanda), UFAL < dudaramos.a国gmail.com > Alessandra Van Der Ley (graduanda), UFAL < alessandracvanderley@gmail.com > Janaina Freitas Silva de Araúio (graduanda) UFAL < jana.f.araujo@gmail.com > 